\title{
Maíz y balché. Una revisión de la iconografía de los murales de Tulum
}

\author{
Corn and balché. A Review \\ of the Tulum Murals Iconography
}

\author{
Eduardo PÉrez de Heredia \\ Historiador independiente, Yucatán, México
}

PÉTER BíRÓ

Investigador independiente, Hungría

SyLVIANE BOUCHER

Instituto Nacional de Antrolopología e Historia, Centro Yucatán, México

\begin{abstract}
Resumen: En este trabajo presentamos una revisión de los murales de los Templos del Dios Descendente (Templo 5) y de los Frescos (Templo 16) en la ciudad prehispánica maya de Tulum, Quintana Roo. En primer lugar, se analizan algunos de los personajes ataviados como deidades, en especial Chahk, K'awil, Quetzalcóatl y Xólotl. En segundo término, se estudia la parafernalia ritual, mayormente compuesta de objetos cerámicos en forma de urnas-efigie, incensarios, ídolos, contenedores con ofrendas de maíz en diferentes preparaciones o grandes ollas para contener líquidos, y se presentan sus contrapartes en el registro arqueológico de la época. Después se abordan los motivos zoomorfos y fitomorfos, como los marcos con grecas trenzadas rematadas en cabezas de serpiente, así como los elementos vegetales que identificamos con la flor y los frutos del árbol del balché. Finalmente se integran todos estos datos para interpretar el significado de los murales de Tulum con relación al periodo otoñal de dobla del maíz y cosecha de primicias, que coincide con la floración del balché y el inicio de la cosecha de la miel de tajonal.
\end{abstract}

Palabras claves: mayas; Tulum; Posclásico Tardío; pintura mural; cerámica; iconografía.

ABstract: In this paper we present a review about the murals located in the Temples of the Descending God (Temple 5) and the Frescos (Temple 16) at the pre-Columbian city of Tulum, Quintana Roo. We first study some of the characters dressed as gods, as Chahk, K'awil, Quetzalcóatl, and Xólotl. Secondly, we analyze the ritual 
paraphernalia, mostly composed of ceramic objects in the form of effigy urns, incense burners, idols, containers with offerings of corn in different preparations, and large jars used to contain liquids, presenting correspondences with the archaeological record. Afterwards, we analyze the intertwined serpents, as well as the vegetal elements that we identify with the flower and fruits of balché tree. Finally, these data are integrated in order to interpret the meaning of the Tulum murals in relation to the practice of bending over the maize stalks in the autumn, and also to the first fruits harvest, which coincides with the flowering of the balche tree and the beginning of the harvest of tajonal honey in Yucatán.

KeYwords: Mayas; Tulum; Late Postclassic; mural paintings; ceramics; iconography.

RECEPCIÓn: 27 de noviembre de 2019.

ACEPTACIÓN: 13 de marzo de 2020.

DoI: https://doi.org/10.19130/iifl.ecm.57.2021.18655

\section{Introducción}

Desde que recibieron la atención de los estudiosos occidentales, han sido varios los intentos de interpretación de las pinturas murales de la ciudad prehispánica de Tulum, Quintana Roo, México, aunque todos coinciden, en lo general, en la relación de los murales con la agricultura del maíz (Lothrop, 1924; Fernández, 1945a; 1945b). Concretamente, en este artículo trataremos de probar que los murales representan rituales de primicias de cosecha con la presentación de elotes y tamales, y la libación del balché, una bebida fermentada en la que se emplea miel; resaltando que, hacia octubre, en el norte de Yucatán coinciden la cosecha de primicias del maíz, la gran cosecha de miel de tajonal y la floración del árbol del balché.

En este trabajo presentamos una revisión de los murales de los Templos del Dios Descendente (Templo 5) y de los Frescos (Templo 16) (ver Figuras 1-3) y sus diversos elementos iconográficos constituyentes. En primer lugar, se estudian algunos de los personajes que muestran atavíos de diferentes deidades. Después se examina la parafernalia ritual, mayormente compuesta de objetos cerámicos en forma de incensarios efigie, ídolos, contenedores con ofrendas de maíz en diferentes preparaciones y grandes ollas para contener líquidos, de las cuales se presentan contrapartes en el registro arqueológico de la época. Finalmente se abordan los marcos con grecas trenzadas rematadas en cabezas de serpiente y adornadas con nudos, así como los elementos vegetales que identificamos con la flor y los frutos del árbol del balché.

Las ruinas de Tulum fueron conocidas gracias a las exploraciones de George Howe en 1911 y recibieron finalmente la atención de los investigadores de la Carnegie Institution of Washington, siendo descritas brevemente por Sylvanus Morley (1917). Es destacable el trabajo de Samuel K. Lothrop entre 1916 y 1922 (1924), quien identificó por vez primera a Tulum con la Zamá avistada por Juan 
de Grijalva en 1518, y realizó el registro inicial de las pinturas, al igual que el de Miguel Ángel Fernández (1945a, 1945b), quien trabajó en Tulum en 1938 restaurando la arquitectura y pintura mural, además de las contribuciones de César Lizardi (1939), Alberto Escalona (1946) y William Sanders (1960), quien definió su temporalidad a través de la estratigrafía cerámica.

En los años 1916, 1918 y 1922, la Carnegie Institution of Washington realizó trabajos en la zona, barnizando los murales. Apenas dos décadas después, el acelerado deterioro de la techumbre produjo fisuras y desprendimientos; cuando Miguel Ángel Fernández los encontró ya estaban dañados y el barniz se había oscurecido, opacando las pinturas. Fernández consolidó y restauró el edificio, e intervino en los murales retirando el barniz de la Carnegie y repintando algunas partes. Desde los años ochenta, los murales han recibido atención por parte del Instituto Nacional de Antropología e Historia (a través de la Escuela Nacional de Conservación, Restauración y Museografía, ENCRYM, y la Coordinación Nacional de Conservación del Patrimonio Cultural, CNCPC).

Se conservan tres registros en dibujo de los murales: el primero de Thomas Gann y John Held para el libro de Lothrop (1924), donde podemos observar, por el dibujo del templo de los Frescos, que los murales ya estaban bastante deteriorados en esa época, con grandes espacios faltantes o lagunas. El segundo corresponde a Miguel Ángel Fernández y el tercero es una reconstrucción de Felipe Dávalos de 1974, para el estudio de Arthur Miller (1982), el más frecuentemente reproducido y el que usaremos en este trabajo (Figuras 1-3).

Los ejemplos mejor conservados de pintura mural en la costa oriental corresponden a los murales del Templo del Dios Descendente (Estructura 5) y del Templo de los Frescos (Estructura 16) de Tulum; éstos son de la misma temática en lo general, aunque los segundos son más extensos y complejos; pertenecen al periodo del Posclásico Tardío (Vaillant, 1938: 565; 1940: 299-305), por su parecido con el estilo de la cerámica del mismo nombre, así como de los códices mayas, del grupo Borgia, de los códices mixtecos, y de una serie de murales mesoamericanos, los cuales forman parte del también llamado estilo Internacional (Robertson, 1970: 88; Lombardo, 2001). El concepto de estilo Mixteca-Puebla fue acuñado por George Vaillant (1938: 565), quien los ubicó desde el norte de México hasta Centroamérica. Para el caso de Tulum, Robertson propuso el término de estilo Internacional (1970: 88). Michael Smith (2003: 182) y Taube (2010: 146) coinciden en usar dicho término; este estilo estaría comprendido por cuatro sub-estilos regionales: azteca, mixteca-puebla, maya de la costa y tierras altas de Guatemala.

La técnica pictórica de ambos murales es semejante, con motivos y figuras delineados en negro, dentro del llamado estilo Azul Negro (Robertson, 1970; Miller, 1982: 71; Lombardo, 2001: 143-150), que correspondería al periodo Posclásico Tardío. Están realizados sobre un fino revoque de cal, a mano libre y empleando un pincel de punta redondeada (Fernández,1945b). El estilo ha sido caracterizado por una paleta que maneja dos tonos de azul y negro sobre fondo blanco, y una línea de dibujo muy delgada dentro de una composición simétrica y equilibrada, 
con registros horizontales subdivididos en paneles rectangulares separados por franjas decorativas con motivos simbólicos, destacando la disposición de una capa acuática, una terrestre y otra celeste (Lombardo, 2001: 143-146). Robertson (1970: 85) señaló que las máscaras, los atuendos y los objetos portados son los que confieren individualidad a los personajes, cuyos rasgos fisonómicos son convencionales, y donde las figuras humanas se pueden dividir en partes separables e intercambiables, resultando en posiciones y gestos rígidos y convencionales. En este mismo tenor, Miller (1982: 55) comparó las figuras con muñecos de papel cortado, que visten máscaras, capas, pectorales y tocados intercambiables.

Claramente, la presentación de las escenas divididas en registros horizontales, separados por elementos como cuerdas o serpientes entrelazadas, es un rasgo que aparece antes en Chichén Itzá, por ejemplo, en el Templo Inferior de Jaguares, y tiene su origen en el área Puuc a inicios del siglo ix. Los murales de Tulum son de menor complejidad que las representaciones de Chichén Itzá, donde aparecen decenas de personajes en cada escena, cada uno con diferentes atributos; y mientras en Chichén los rostros de los personajes representados son realistas, en el estilo de Tulum son estandarizados. Lo importante radica en las insignias que portan y en las acciones que realizan, siendo de menor importancia la identidad personal del actuante o portador.

El más sencillo de los dos analizados, el mural del Templo del Dios Descendente (Estructura 5), consiste en una escena principal enmarcada por una franja superior considerada como una banda celeste y una inferior con motivos acuáticos (Figura 1). Dos escenas similares de un personaje sentado sobre un trono, frente a una figura antropomorfa de menor tamaño, forman el foco principal, mientras que a ambos lados dos seres sobrenaturales alados descienden de la banda celeste.



Figura 1. Templo del Dios Descendente, Estructura 5, Tulum (Reconstrucción de Dávalos, en Miller, 1982: lám. 28).

Los murales del Templo de los Frescos (Estructura 16) ocupan varios muros basales, molduras, columnas e incluso la fachada (Figura 2). La disposición es 
similar a la de la Estructura 5, pero aparecen más registros horizontales poblados de figuras y separados por líneas entrelazadas que culminan en cabezas de serpiente. En el Templo 16 los murales ocupan todo el espacio de los muros basales y además el espacio de la moldura media, donde aparece una banda con personajes. De arriba hacia abajo encontramos una banda superior con una greca de tipo cheurón (chevron) y flores vistas frontalmente, seguida del Registro 1 que ocupa la moldura y que aparece separado de la decoración del muro basal por otra banda decorativa similar a la superior.



Figura 2. Templo de los Frescos, Estructura 16, Tulum, fachada poniente, Murales 1, 2 y 5 (Reconstrucción de Dávalos, en Miller, 1982: lám. 37).

De acuerdo con interpretaciones anteriores, los tres niveles del cosmos mesoamericano, inframundo, plano terrestre y reino celeste, aparecen ordenados jerárquicamente en ambos murales de Tulum (Lombardo, 2001: 145). De los tres registros del muro basal del Mural 2 del Templo 16 (Figura 3), los dos inferiores están enmarcados por volutas curvilíneas a manera de fauces, semejantes a otros motivos que representan la tierra, cuyo interior se concibe como un lugar acuático donde moran los dioses del inframundo. De ser así, las dos escenas inferiores corresponderían al reino sobrenatural del inframundo, y el registro que se les sobrepone, encima de las fauces, representaría entonces el mundo real sobre la tierra y, finalmente, el registro superior correspondería al reino celeste.

En el Templo 5 aparece de nuevo el mundo subacuático, separado por una banda de piel de jaguar del reino terrestre donde se desarrolla la ceremonia 


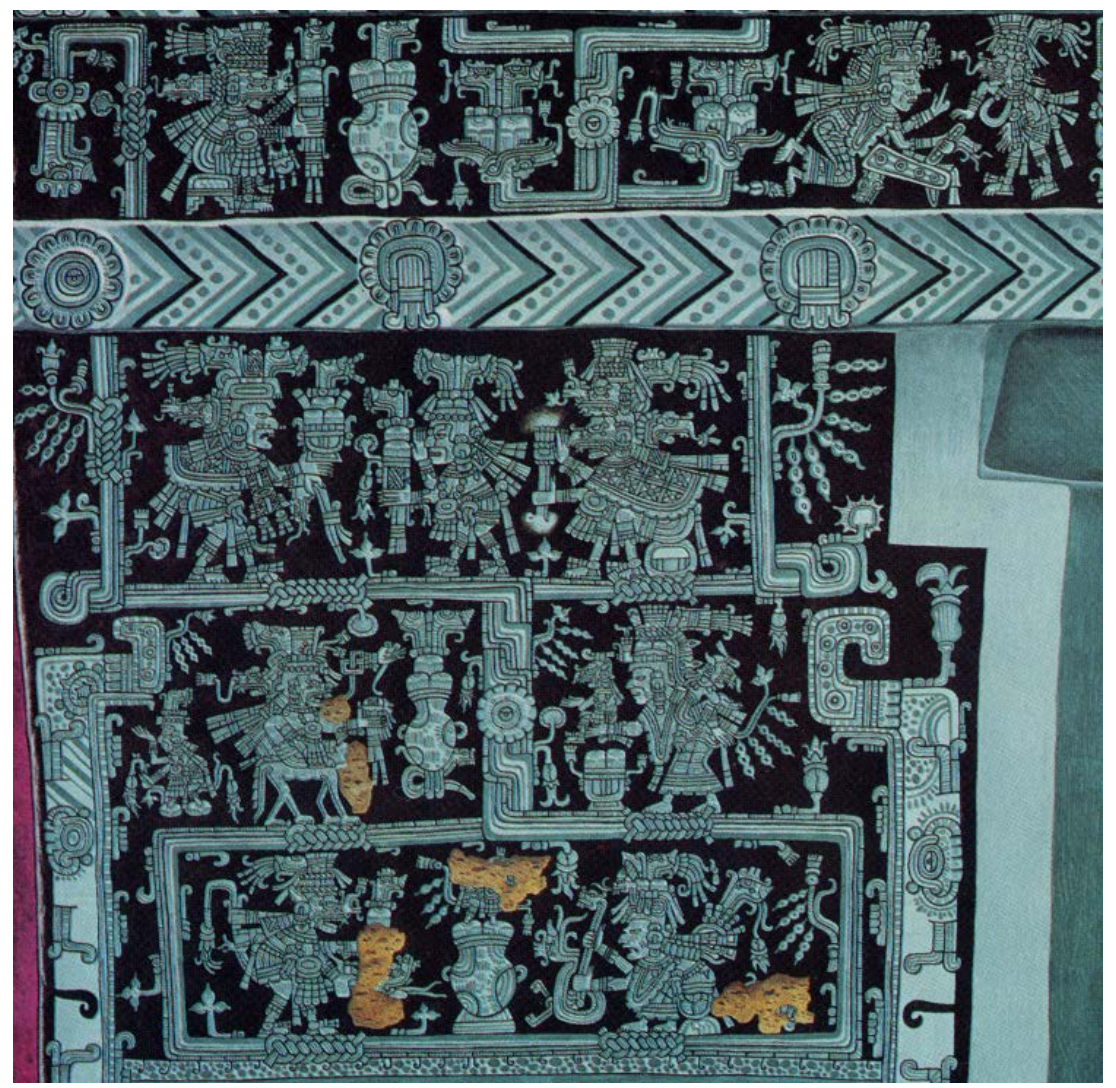

Figura 3. Escena central del Mural 2 del Templo de los Frescos (según Dávalos, en Miller, 1982: lám. 37).

central, apareciendo también la banda celeste de la que desciende una deidad alada. Muy influyentes en las últimas décadas han sido las interpretaciones de Arthur Miller (1982: 85-91), quien encontró motivos solares y venusinos, así como referencias al inframundo (1982: 97), proponiendo una dicotomía vida/muerte entre los paneles superiores e inferiores, mientras que las cuerdas entrelazadas se relacionarían con el mito del kusansum, recogido por Tozzer (1907), que lo identifica con una especie de cordón umbilical (Miller, 1982: 91-95).

En cuanto a la cronología de los murales, Miguel Ángel Fernández (1945a; 1945b) distinguió dos épocas arquitectónicas: la más antigua corresponde a piezas muy amplias, con un intercolumnario interior cubierto de techo plano de concreto con vigas de jabín, y otra superpuesta, de bóveda maya primitiva sin piedra especializada. En las columnas de El Castillo, Fernández reportó tres capas pictóricas; las dos más antiguas, en negro y verde cobalto, pertenecen al estilo 
Azul Negro de las Estructuras 5 y 16, mientras que la más reciente muestra un mayor repertorio cromático, incluyendo rojo, azul, verde, ocre y negro (Fernández, 1945b: 110).

En su estudio del sitio, William Sanders (1960) fue el primero en proponer que Mayapán y Tulum fueron contemporáneos, opinión que compartimos los autores de este trabajo, aunque existen otras dataciones discrepantes. Para Miller (1982), Tulum es un fenómeno posterior a 1400, es decir que correspondería al final de Mayapán. Por su lado, Rubén Maldonado (1987: 37) coincide en que la ciudad floreció después de 1400, es decir en el siglo xv, que encuadraría con el periodo del fin de Mayapán, aunque el mismo autor admite fechamientos estilísticos más tempranos para los murales, que datarían para 1100 d. n. e. en la Sub 1 del Castillo, y para 1250 en el caso de la Estructura 5 (Lombardo et al., 1987: 52). También hay que mencionar a Milbrath y Peraza (2003), quienes sugirieron que Mayapán podría datar tan temprano como 1100, notando un posible traslape con Chichén Itzá, aunque nosotros nos inclinamos por una fundación de Mayapan más tardía, a fines del siglo xII (Schmidt, Biró y Pérez de Heredia, 2018). Finalmente, Merideth Paxton (2010) ha propuesto que los murales no serían del Posclásico, sino anteriores, señalando parecidos con la iconografía de la cerámica del tipo Chocholá del periodo Clásico Tardío, posición que no compartimos.

Reiteramos que, de acuerdo con Sanders (1960), entendemos que la historia de Tulum es esencialmente contemporánea a la de Mayapán, con la que comparte estilos arquitectónicos y cerámicos. Su desarrollo habría sido paralelo, cubriendo por lo tanto los siglos xIII y xIV, lo que permitiría un tiempo suficiente para la evolución de la pintura de Tulum que muestran los diferentes estilos de pintura mural detectados en capas inferiores de estuco (Fernández, 1945b). En nuestra opinión, la calidad de los murales del estilo Azul y Negro y sus características, tan distanciadas del estilo de Chichén Itzá en el Posclásico Temprano, apuntan a un fechamiento ca. 1250-1350 para los murales de los Templos 5 y 16, que corresponderían al apogeo del sitio.

\section{Personajes}

De acuerdo con Lombardo (2001: 146), "en la iconografía de este estilo todos los personajes son dioses. La mayoría se encuentran ejecutando actos rituales, aparentemente propiciatorios — como quemar copal en grandes urnas- principalmente para la fertilidad, pues los realizan los dioses del agua, de la tierra, del nacimiento o germinación y del maíz".

Lothrop (1924) identificó varios dioses, como el Dios A, Dios de la Muerte; B, Chahk; C, K’uh; D, Itzamná; E, Dios del Maíz, y K, K’awil (según la nomenclatura de Schellhas, 1904), y a Ehécatl, así como la figura de una joven diosa, reconociendo asimismo figuras humanas, como una mujer joven bailando. Realizó también identificaciones puntuales, entre ellas las bandas de constelación, las 
serpientes entrelazadas, las figuras de mazorcas, peces y flores, y ofreció una interpretación general que enfatizaba correctamente el vínculo de los murales con el cultivo del maíz y las deidades asociadas a ella, donde destacaría el propio Dios del Maíz (Lothrop, 1924: 53-59). Por su parte, Fernández (1945a; 1945b) reconoció a los Dioses D y E, así como a una sacerdotisa, y los otros elementos como las mazorcas, las vainas de flores y las grecas de serpientes entrelazadas, coincidiendo con Lothrop en que los murales remiten a ceremonias relacionadas con el ciclo del maíz; además, encuentra elementos que se relacionarían con Venus y el Sol.

Es también notorio el estudio de Milbrath (1999: 147-148) sobre la luna y sus representaciones en los murales de Tulum, donde los personajes femeninos son identificados como deidades lunares, concluyendo que Tulum estaba dedicado al culto de las diosas lunares, especialmente los aspectos avejentados de la luna (Milbrath, 1999: 148). Finalmente, Taube (2010) ha examinado el simbolismo de las flores de los murales de Tulum y la costa oriental comparándolos con otros ejemplos del estilo Internacional, y proponiendo relaciones con el culto del Sol y de Venus. A continuación, revisaremos algunas de las deidades de los murales.

K'awil

La deidad que desciende de la banda superior en la Estructura 5 de Tulum (Figuras 1, 4c) puede identificarse con el dios K'awil en su aspecto alado. Una de las primeras ocurrencias de este dios en forma glífica aparece en la inscripción de la Casa Colorada de Chichén Itzá, donde encontramos el nombre completo como Yax Uk'uk'um K'awil, "verdes son las plumas de K'awil" (Grube, Lacadena y Martin, 2003: II-40). También aparece en forma policromada en Santa Rita (Figura 4d), y en Chichén Itzá, por ejemplo en la tapa de bóveda del Templo de los Búhos (Figura 4b), datada recientemente para 1144 (Schmidt, Biró y Pérez de Heredia, 2018). Un referente aún más antiguo en la misma ciudad puede fecharse para 998 d. n. e., en los paneles de los cuerpos escalonados de la Pirámide de El Osario (Figura 4a; Schmidt, 2007: fig. 20). La escena de Tulum no es completamente simétrica, pues a la izquierda el K'awil desciende para tomar las ofrendas dispuestas sobre un incensario, mientras que a la derecha el K'awil de plumas alarga su mano hacia un elote doblado que cuelga de la planta de maíz (véase Figura 1).

El dios K'awil aparece también en el Templo de los Frescos o Estructura 16, pero no en su versión alada, sino con cuerpo antropomorfo (véase Figura 2). En total, aparece cuatro veces en el Templo de los Frescos, siendo la deidad más representada de los murales. Este personaje se ilustra realizando una serie de acciones, como la presentación de ofrenda de elotes, la presentación de la estatuilla del Dios del Maíz, ambas sentado sobre un trono, y otras dos más de pie, con un sahumador en forma de serpiente de lengua bífida y la otra con las manos vacías. 




a



C



b



Figura 4. a) El Osario, detalle (Schmidt, 2007: fig. 20); b) Tapa de bóveda del Templo de los Búhos (Willard, 1926: 248); c) Templo 5, Tulum; d) Santa Rita Corozal.

Chahk

El dios Chahk aparece tanto en el Templo 5, de pie y con las manos extendidas, como en el Templo 16, donde se muestra sentado sobre una piedra redondeada con el signo $t z^{\prime} a m$, trono, y con un objeto como cetro o perforador en la mano (Figuras 5a y b). En ambos casos porta un tocado del Dios K'awil y un rostro de la serpiente Chahk en su nuca, un rasgo en común con el tocado de otros personajes.

Una imagen muy semejante de Chahk con tocado de K'awil sobre la cabeza, semejante a la de Tulum, aparece en la página 65 del Códice de Dresde (Figura 5c), donde además sostiene una figura en las manos en forma de cabeza de K'awil. 
Más allá del extraordinario parecido, es importante señalar que en el códice contamos además con un texto asociado, que se lee: utzak k'awil ha'al ok chahk o'och k'in nal?; lo que puede traducirse como 'Ha'al Ok Chahk (Tempestad de la pierna de Chahk) sostiene a K’awil, será la abundancia (o alimento), será el tiempo de maíz?'. ${ }^{1}$ Por lo tanto, la representación de Chahk con el tocado de K'awil es una imagen asociada con una cosecha exitosa.



a

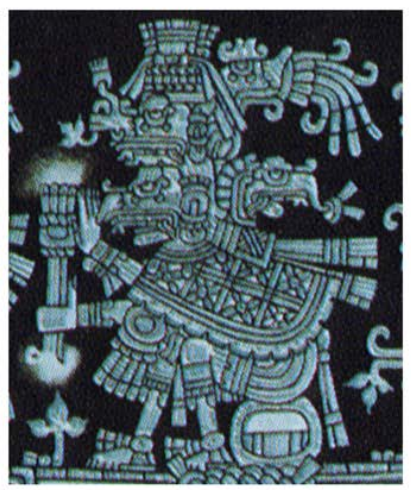

b



C

Figura 5. Representaciones del dios Chahk. a) Templo 5;

b) Templo 16; c) Códice de Dresde: 65a.

\section{Quetzalcóatl y Xólotl}

Varios autores han destacado rasgos que muestran una relación de Tulum con el planeta Venus, y por ende con el culto al dios Quetzalcóatl (Fernández, 1945b; Miller, 1982). Aquí queremos hacer notar que el personaje del Mural 4 del Tem-

${ }^{1}$ Traducción de Péter Bíró (realizada en 2019) y Bricker y Bricker (2011: 515). En el caso de tzak, al contrario de muchos que lo traducen como "conjuring" o sea "conjurar", el significado del verbo es “agarrar" en proto-ch'olano y también en ch'olano clásico (Kaufman y Justeson, 2003: 903). Aunque en yucateco colonial el significado de tzak, entre otras cosas, es "conjurar nublados, conjuro idolátrico de los vientos” (Barrera Vásquez, 1980: 850), según la particular escena del Dresde 65a, Chahk agarra la máscara de K'awil y también lleva un tocado del mismo dios; es por ello que hemos usado el significado de "agarrar". 
plo 16 puede identificarse precisamente con el dios Quetzalcóatl (Figura 6a). Como otras figuras del mural, el personaje está sentado en un trono y sostiene una ofrenda de maíz en la mano derecha. En la faz del personaje, que muestra la nariz perforada por una nariguera de barra, destacan las manchas negras sobre la mejilla, uno de los signos para Quetzalcóatl. Además, su largo tocado es único entre los que hallamos en los murales de Tulum y consiste en una cabeza de serpiente que continua con el cuerpo cubierto de plumas sobre la espalda, es decir, la serpiente emplumada. Otro interesante motivo que refuerza la identificación serían las dos cabezas de pájaros con picos de pato que simbolizan a Ehecátl, el Dios del Viento, uno de los aspectos de Quetzalcóatl.

La figura frente a Quetzalcóatl, también sentada en un trono, puede identificarse por el tocado con Xólotl, uno de los aspectos de Quetzalcóatl en el altiplano mexicano; pero al contrario que aquél, no muestra su nariz perforada y es de menor tamaño. Igualmente está sentado sobre un trono similar, pero de menor tamaño, y presenta una ofrenda semejante (Figura 6b). El tocado es lo que lo diferencía, consistiendo en una cabeza de perro o cánido, que debido al contexto proponemos que se trate de Xólotl, el hermano gemelo de Quetzalcóatl.

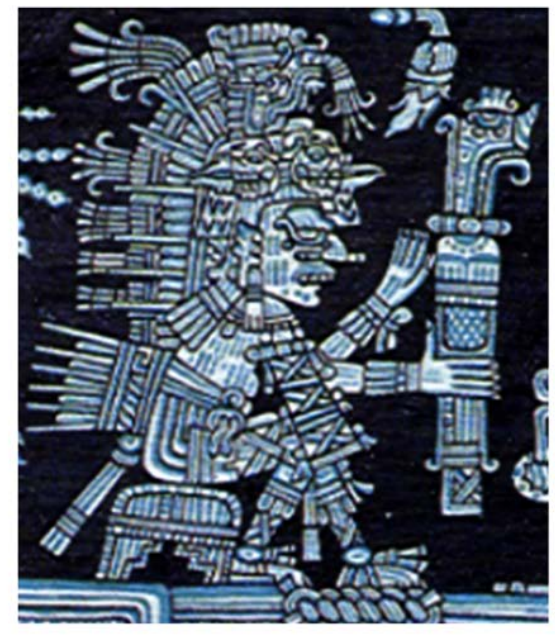

a

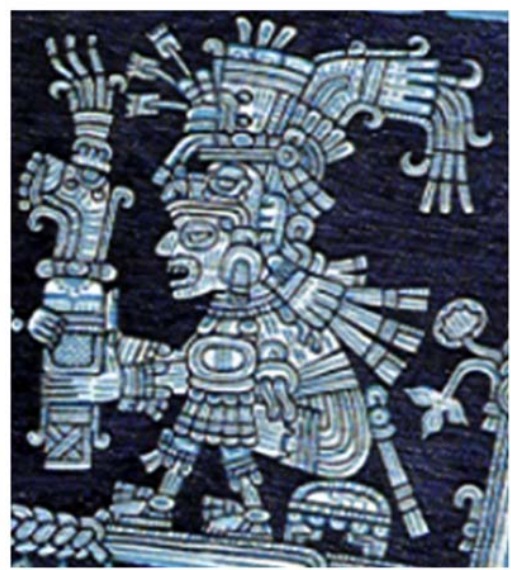

b

Figura 6. a) Personaje con tocado de Ehécatl-Quetzalcóatl; b) personaje con tocado de cánido, posiblemente Xólotl. Templo de los Frescos, Estructura 16, Santuario Interior, Murales 4 y 6 (Reconstrucción de Dávalos, en Miller, 1982: lám. 37).

Otra figura de un cánido, que identificamos como un coyote (Figura 7b), se distingue de las otras por aparecer sentada sobre un trono de cuadrúpedo, de largas extremidades, cuya cabeza se había ya perdido cuando las primeras exploraciones, y que impide una identificación inequívoca del animal, pero por 
su cola escalonada podría representar también un coyote. Consideramos que la contraparte arqueológica de esta deidad del mural aparece en un incensario Chen Mul de Mayapán, en forma de coyote, con idéntico tocado de mazorcas y la flor en la frente. Peraza y Milbrath (2010) han identificado esta figura con un mono, pero en nuestra opinión el hocico es demasiado largo para sustentar tal idea; además, la lengua extendida funciona como signo ubicuo para los perros y los coyotes (Figura $7 \mathrm{a}$ ).



a

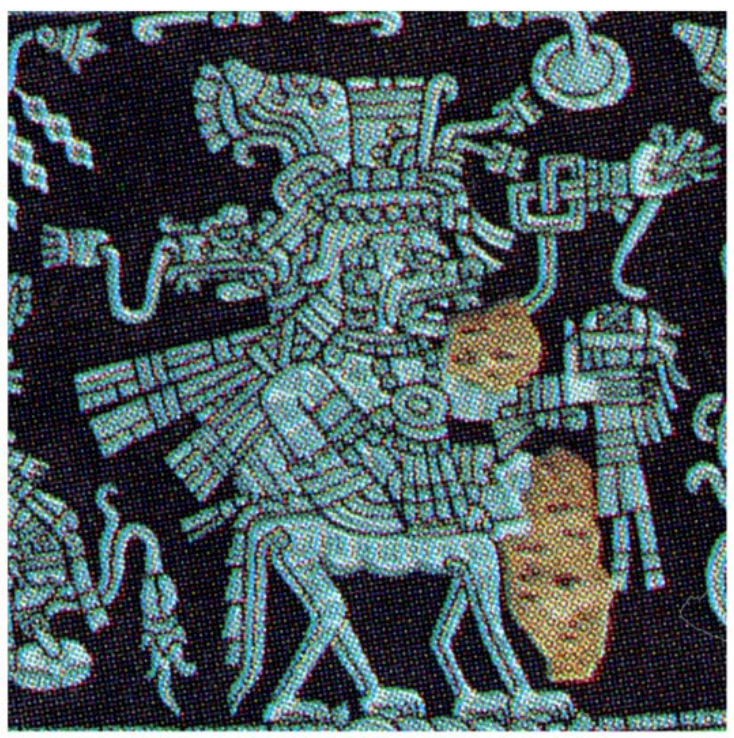

b

Figura 7. a) Incensario de Mayapán (Peraza y Milbrath, 2010);

b) Mural del Templo 16 .

\section{Objetos cerámicos}

Quizás debido al escaso número de representaciones disponibles, la identificación tipológica cerámica de las vasijas representadas en el arte maya no ha sido atendida de manera metódica. Un esfuerzo pionero fue el de Arthur Miller, quien presentó varias identificaciones para los murales de la costa oriental incluyendo Tulum y Xelhá (Miller, 1982: 57-60, figs. 95, 96, 97, 100, 101, 111, 112). También un número importante de identificaciones de vasijas han sido mostradas en la pintura mural de Calakmul (Boucher y Quiñones, 2007) y dos identificaciones particulares han sido propuestas en Chichén Itzá (Pérez de Heredia, 2010: 145, figs. 95-96; Bíró y Pérez de Heredia, 2016). Diferentes elementos presentes en 
los murales de Tulum pueden identificarse como objetos de cerámica, y a continuación se analizarán sus contrapartes arqueológicas. Entre ellas encontramos desde formas de contenedores para líquidos y alimentos, hasta cerámica ritual, que incluye incensarios de varios tipos y estatuillas.

\section{Incensarios efigie}

El primer objeto de cerámica que identificamos en los murales del Templo 5 de Tulum es la representación de las urnas modeladas antropomorfas conocidas como 'incensarios efigie', del tipo Chen Mul Modelado (personajes centrales de la Figura 1; Figuras 8d y f), emblemáticas de Mayapán y su periodo de apogeo (Smith, 1971). Esta cerámica no había sido identificada anteriormente en los murales, aunque Paxton (2010) ha remarcado que la iconografía de ciertas partes estandarizadas intercambiables de los murales de Tulum es compartida por la de los incensarios Chen Mul, construidos también a base de partes estandarizadas intercambiables; por su parte, Joseph Ball (citado en Miller, 1982: 59) sugirió que las pequeñas figuras sostenidas en las manos en el mural del Templo 5, que nosotros identificamos como estatuillas (ver más adelante), podrían representar incensarios efigie.

Nosotros proponemos que, aparte de las semejanzas iconográficas y temáticas entre los murales y los incensarios, los personajes de mediana altura en el mural del Templo 5 corresponden de hecho a incensarios efigie. Por ejemplo, la verdadera relación de tamaño (Figuras 8a y b), muestra que no se trata de dos seres semejantes, dado que uno casi dobla en altura al otro.

Los incensarios efigie aparecen en el registro arqueológico del Posclásico asociados con el apogeo de Mayapán, encuadrados por Robert Smith (1971) en el Complejo Cerámico Tases (1300-1450 d. n. e.), bajo el tipo Chen Mul Modelado (Figura 8c, e, g). Los incensarios efigie se caracterizan por su elaborada factura, ya que fueron modelados, moldeados, aplicados y pintados. Milbrath et al. (2008) han notado que algunos representan deidades del Posclásico representadas en códices del centro de México, mientras que otros remiten a códices mayas y a murales de sitios como Tulum y Santa Rita (Boucher y Palomo, 2005; Taube, 1992). Presentes en el repertorio conocido de incensarios Chen Mul aparecen al menos diez dioses, siendo los más comunes Chahk, Itzamná, el Dios de la Muerte, el Dios del Maíz y el Dios de los Comerciantes (respectivamente Dioses B, D, A, E y M según la nomenclatura de Schellhas 1904; Milbrath et al., 2008). Ciertos incensarios representarían a deidades que mezclan rasgos de dioses mayas y mexicanos, mientras que otros se pueden identificar con deidades de los códices del centro de México, tales como Tlazoltéotl, Tlahuizcalpantecuhtli y Xipe Tótec. La llegada de estas influencias foráneas sería resultado del contacto comercial con las tierras altas centrales del altiplano (Milbrath y Peraza, 2003).

En cuanto a su función, Smith (1971: 210) propuso que las pequeñas perforaciones del fondo de la vasija, y en sus laterales, tenían la función de avivar la 


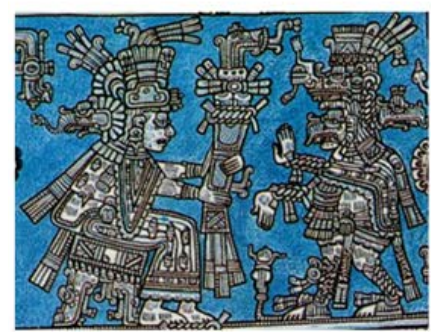

a



d



b

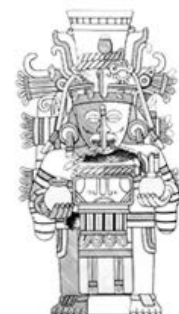

C



e



f



g

Figura 8. a, b) Comparación de altura entre el personaje y el incensario; c) dibujo de un incensario de Mayapán (Smith, 1971); d-g) comparaciones de incensarios efigie del mural con posibles contrapartes arqueológicas.

quema de incienso en su interior, ya que es palpable en el ennegrecimiento del fondo de todos estos incensarios; asimismo, reportó restos de copal hallados aún adheridos al fondo de algunos de ellos. En el caso concreto de Mayapán, según Masson y Peraza (2005), el uso principal de los incensarios efigie Chen Mul sería el de quemar incienso en una variedad de ceremonias diferentes, reportándose en entierros, basureros, ofrendas enterradas y depósitos asociados con altares. Algunos contextos parecen sugerir que las piezas fueron rotas a propósito y diseminadas en otro lugar. Estos autores también detectan la asociación de ciertas clases con localidades específicas, como una concentración de representaciones relacionadas con Venus en el grupo Q80 (Masson y Peraza, 2005).

\section{Estatuillas}

Relacionadas con los llamados incensarios efigie existen otras formas modeladas en el mismo tipo cerámico Chen Mul; se trata de estatuillas más pequeñas que carecen de urna o recipiente en su parte trasera, y que podrían ser los ídolos 
mencionados por Landa (2008). Éstas tienen su contraparte en los murales de Tulum en la forma de pequeñas estatuillas que son portadas en la palma de la mano por dos personajes de la Estructura 16. Por ejemplo, dos estatuillas, esta vez del dios Chahk, son portadas por la Diosa Joven de la Luna, una en su mano y otra en su antebrazo (Figura 9b). Esta figura de Chahk tiene su inequívoca contraparte en una estatuilla hallada en Mayapán (Figura 9a; Barrera et al., 2001: 36, catálogo 10). Estas figurillas se usan en los murales de manera diferente a los incensarios efigie Chen Mul, aunque representan deidades similares.



a



b

Figura 9. a) Estatuilla del tipo Chen Mul de Mayapán (Barrera et al., 2001: 36, cat. 10); b) Estatuilla similar en el Templo de los Frescos

(Reconstrucción de Dávalos en Miller, 1982).

\section{Contenedores para líquidos}

Grandes contenedores, en forma de ollas o cántaros de doble asa y base convexa al exterior, aparecen en los murales de Tulum (Figuras 10a y b). En nuestra opinión, que desarrollaremos más adelante, estas ollas podrían haber servido para contener la bebida alcohólica fermentada con miel que se consumía, de acuerdo con las fuentes, en las ceremonias religiosas: el balché.

Las ollas de base convexa únicamente se mantienen en pie por medio de soportes anulares independientes, muchas veces hechos de cestería, llamados $o k$ en maya yucateco (Barrera, 1980: 595). En uno de los ejemplos de los murales este soporte adquiere la forma de una serpiente trenzada (Figura 10b). Como mostró Lothrop (1924: 57, fig. 28a), dicha asociación de la serpiente y la vasija aparece también en el Códice Madrid (Figura 10c). Las ollas de los murales están decora- 
das en su superficie con líneas concéntricas de figuras semicirculares, las cuales también aparecen decorando la piel de la serpiente en el códice.



a



b



C

Figura 10. Ollas: a, b) Templo de los Frescos; c) Códice Madrid (1967: 35).

La identificación más cercana en su forma a estas grandes ollas son las del repertorio del tipo Mama Rojo, características de Mayapán (Smith, 1971: 61-63, fig. 38), que presentan dos asas horizontales; muchas de ellas son de grandes dimensiones, aunque quizás no tanto como las representadas en los murales. Sin embargo, existen otras vasijas sin engobe de mayores dimensiones, como el tipo Kanasín Rojo sobre sin engobe (Smith, 1971: 91, fig. 60l). Los ejemplares mayores de ollas Mama Rojo contendrán unos 12 litros aproximadamente (Figura 11), pero las grandes ollas Kanasín Rojo sobre sin engobe tienen cerca de un metro de altura y un volumen aproximado a los 24 litros.



Figura 11. Olla Mama Rojo de Mayapán (Barrera et al., 2001: 36, cat. 71). 
En los murales de Tulum aparecen contenedores con soporte de pedestal cubiertos con tamales y elotes (Figuras 12f-k), que Miller identificó con el tipo cerámico Chiquilá, presentando un ejemplo de El Meco (1982: 59, fig. 100). La identificación formal más cercana en el inventario cerámico de Mayapán apunta especialmente a las vasijas con soporte de pedestal del tipo Cehac Hunactí Compuesto (Figuras 12a-d). Este tipo cerámico fue definido por Smith, quien lo encuadra en su discusión de los Complejos Hocabá del Posclásico Medio (Smith, 1971: 135, 207-209) y Tases del Posclásico Tardío, aunque por alguna razón no lo incluye en su lista de tipos por complejo para este último periodo (Smith, 1971: 136), quizás por ser una continuidad en el tiempo del complejo Hocabá: "Actually 41.4 per cent of the ceramic material found in the Tases Ceramic Complex is a carry'over from the Hocaba ceramic complex. This carry over includes [...] Mayapan Unslipped Ware" (Smith, 1971: 207). También hay ejemplos de incensarios de pedestal en el tipo Panabá sin engobe (Smith, 1971: 47, fig. 30a).

Estas formas son descritas usualmente en la literatura arqueológica como incensarios (Brainerd, 1958; Smith, 1971) y muestran muchas veces huellas de hollín en su interior, lo que da pie a pensar que, al igual que en los incensarios Chen Mul, se quemaban sustancias (incienso) en ellos. En los murales, las vasijas con textiles están normalmente decoradas con el signo de las bandas cruzadas en el cuerpo de la vasija o en los textiles que cuelgan de ellas. Por el contrario, aquellas que claramente son de soporte de pedestal muestran una decoración de bandas verticales (Figuras 12f, g y h); volutas que podrían representar humo o flores emergen en ocasiones a ambos lados de las vasijas pintadas en los murales, las cuales sostienen tamales, un trenzado y, frecuentemente, elementos que han sido identificados con mazorcas de maíz o elotes.

Las ofrendas en forma de tamales y elotes (Figura 13), a veces adornados con cuentas de jade, están en ocasiones separadas de ellas por un delgado soporte trenzado. La base de estas vasijas en los murales es en ocasiones difícil de apreciar, dado que muestran colgaduras de textiles que ocultan la parte inferior. En resumen, los posibles objetos cerámicos representados en los murales de Tulum concuerdan con cerámicas del registro arqueológico del periodo asociado al auge de la ciudad de Mayapán, y también aparece en casi todas las ciudades del norte peninsular en esos tiempos, como Mayapán, Chichén Itzá y, por supuesto, Tulum y otros lugares de la Costa Oriental.

Los incensarios aparecen tanto por separado, dispuestos sobre el suelo, como en las manos de algunos personajes, y en estos casos la base de los recipientes no se muestra pues queda oculta por los ropajes textiles (Figuras 12i, j y k). Incensarios de soporte pedestal en los que inequívocamente se quema copal aparecen en los códices, por ejemplo, en el Madrid, página 39 (Figura 12m). En este caso, se trata de un incensario de pedestal con aplicaciones circulares cónicas que asemejan a la vasija con una ceiba (Smith, 1971: 49, figs. 31a y b), los 




a



$f$



i



b



C



d



$\mathrm{h}$



I



k



j



$\mathrm{m}$

Figura 12. Contenedores de ofrendas: a-e) incensarios del Tipo Cehac Hunactí Compuesto de Mayapán (Smith, 1971: figs. 62a-e); f, g, h) murales del Templo 16; i, j, k) murales del Templo 5; l) murales de Xelhá; m) Códice Madrid: 39c. 




Figura 13. Vasija de soporte pedestal con ofrendas de maíz, Mural del Templo 16.

cuales aparecen también en los murales de Xelhá (Figura 12l) y cuentan con una larguísima tradición en la cerámica maya. En el norte de Yucatán son frecuentes en las vajillas sin engobe de los complejos Cehpech y Sotuta, y en Mayapán estos incensarios-ceiba aparecen en varios tipos, como el Cehac Hunactí (Smith, 1971: 95, figs. 63a-d).

\section{Elementos zoomorfos y fitomorfos}

Aunque la mayoría de los estudiosos puede coincidir en las identificaciones de las deidades o en cuanto a la parafernalia ritual, existe menos consenso en lo que se refiere a otros elementos de los murales que hemos encuadrado bajo el título de elementos zoomorfos y fitomorfos, los cuales añaden información contextual a los rituales realizados por los personajes del mural.

\section{La serpiente entrelazada}

Las escenas de los murales en ambos edificios están separadas por una trenza de dos hileras que culmina en sendas cabezas sobrenaturales y que se encuentra puntuada por decoraciones de trenzas y otros motivos como flores vistas de frente. Las serpientes entrelazadas fueron relacionadas por Miller (1982: 91-95) con la tradición oral del kusansum, recogida por Tozzer (1907: 153), acerca de un cami- 
no blanco suspendido en el cielo, que iba desde Tulum y Cobá hasta Chichén Itzá y Uxmal en forma de una cuerda viva, como un cordón umbilical. Milbrath (1999: 284) sigue a Miller en la relación con el kusansum y sugiere asimismo una asociación con el camino blanco o la Vía Láctea, mientras Taube (2010: 172, fig. 24) las interpreta como serpientes emplumadas relacionadas con Venus-Quetzalcóatl.

También en el Templo Inferior de los Tigres de Chichén Itzá las escenas están enmarcadas, pero la cuerda remata en cabezas de serpiente naturalistas similares. Sin embargo, en los murales de Tulum (Figura 14), las cabezas son de seres sobrenaturales, y al menos una de ellas se identifica con el dios Chahk (Figuras 14b-c), mientras que la segunda, muy semejante, podría relacionarse, por la flor en el labio, con el dios K'awil (Figura 14a), o ser otra advocación del mismo Chahk; el tocado de ambos es también diferente. Por su parte, las cabezas de la serpiente entrelazada en el mural del Templo 5 (Figura 14d) son idénticas y muestran la flor en el labio, con la boca abierta engullendo ofrendas de tamales y elotes.

En los relieves del muro este del Templo Inferior de los Jaguares se muestra que el trenzado de estas serpientes era en realidad un ritual, ejecutado por los pawahtunes (Figura 14e). En el contexto de los murales de Tulum, claramente dedicados a la agricultura del maíz, es posible que tales trenzados se refieran a las medidas tomadas con cuerdas del terreno de la milpa y a las medidas del espacio ritual. La presencia del dios Chahk, dios de la lluvia, y posiblemente de K'awil, deidad de la fertilidad, en el entrelazado de los murales de Tulum, tendría un carácter propiciatorio para el éxito de la cosecha.

Varios elementos puntúan a intervalos regulares la serpiente entrelazada, como trenzas, plantas de maíz y flores. Uno de los rasgos en común entre los incensarios Chen Mul y los murales de Tulum es la presencia repetida de un elemento como nudo trenzado de cuerda (al que comúnmente los investigadores identifican con un petate; por ejemplo, en los antebrazos y piernas de la Figura $5 b)$. Además de ser el petate el símbolo de los reyes y el gobierno en sí, estos trenzados quizás se refieren también a los ancestros o al Inframundo, como en el título b'alun tz'akb'u ajaw (nueve [muchos] señores puestos sobre otros) y en la expresión b'olon tz'akab (muchas generaciones, en yucateco colonial, K'awil en el periodo Clásico) durante el periodo Clásico y también en las fuentes coloniales, como ha propuesto Elizabeth Wagner (2005: 3, 8-40). ${ }^{2}$

\footnotetext{
${ }^{2}$ B'alun tz'akb'u ajaw se mencionó a menudo en las inscripciones del periodo. Tz'akb'u está compuesto por el verbo posicional $t z$ 'ak y el sufijo causativo - $b$ ' $u$ y su significado es "poner sobre otro". Tal vez $t z$ 'akbu' se refiere a los nueve niveles del Inframundo y los ajaw son los dioses que viven en este terreno mitológico. Además, la expresión ix tz'akb’u ajaw funcionó como un título para las mujeres (como la esposa de K'inich Janab' Pakal de Palenque y la madre de K'ahkupakal de Chichén Itzá) y tal vez apunte al concepto de generación en este caso particular. Es muy interesante que entre los mexicas los nueve niveles del Inframundo se denominaban chicnauhtlanepaniuhqui o chicnauhnepaniuhcan en donde nepaniuhqui es participio del verbo nepanoa "juntar-se una cosa con otra o echar una cosa sobre otra" (López Austin, 2016: 136), al igual que tz'akb’u.
} 



Figura 14. Mural del Templo 5: a) posible serpiente K'awil, b) Dios Chahk, c) serpiente Chahk, d) serpientes entrelazadas (reconstrucción de Dávalos, en Miller, 1982);

e) Templo Inferior de los Jaguares, Muro este, Chichén Itzá (dibujo de L. Schele, 1998).

También aparece alternando con los motivos de petates un elemento en forma de flor de muchos pétalos, que en ocasiones muestra un signo de los denominados "ojo de reptil" en su interior (Figura 15a), que ha sido identificado con las estrellas, y que podría representar el concepto de "gran ojo", uno de los nombres de Venus (Milbrath, 1999: 160). El "ojo de reptil" aparece también separado de la flor y se repite en la decoración superior al exterior de la Estructura 16. En un trabajo reciente, Karl Taube (2010) ha examinado algunos elementos particula- 
res de los murales de Tulum, con énfasis en las representaciones de flores que considera remiten a la tradición mesoamericana del Tamoanchan o paraíso florido al que acceden los espíritus de los guerreros (Hill, 1992). Taube (2010: 162) propone que la flor, que lee como nik, refiere al sol, k'in, cuyo glifo es una flor de cuatro pétalos (Taube, 2010: 156 y ss.). Sin embargo, nosotros consideramos que la flor de Tulum es muy diferente, presentando numerosos pétalos en vez de cuatro.

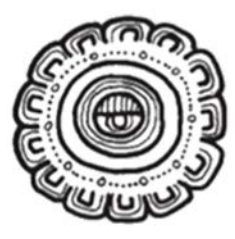

a



b



C



d

Figura 15. Flores de los murales de Tulum; a) según Taube (2010: fig. 7); b) sección de un elote; c) según Taube (2010: fig. 7); d) posible elote con punzón del Códice Dresde: 2a (Förstemann, 1892).

Proponemos una interpretación alternativa para este diseño, que no sería una flor, sino un dibujo de un elote en sección (Figura 15b), mientras que la variante que representa la misma flor y de la que parece emanar una vírgula (Figura 15c), sería el elote con el punzón bakche' clavado. El bakche' es el trozo puntiagudo de madera dura o cuerno de venado que se usa para desprender y despojar a la mazorca de sus envolturas o brácteas durante la cosecha (Barrera, 1980: 27). Una imagen del Dios del Maíz sosteniendo un elemento semejante aparece en el Códice Dresde (Figura 15d). La página D2a, a la que corresponde esta figura, presenta dos dioses y cuatro textos, y forma parte de un almanaque de 52 días con augurios. El primer texto es:

ch'ak b'ah u tuch Jun Ajaw chamal

El ombligo (u tuch) de Jun Ajaw se decapita, [el pronóstico] será mortandad.

El segundo texto es:

o'och? u tuch yatan Ahan?

El alimento? es el ombligo ( $u$ tuch) de Ahan (Dios del Maíz). ${ }^{3}$

${ }^{3}$ Traducciones de Péter Bíró (2020). 
Podemos entender que la representación de la flor se denomina $u$ tuch, como un símbolo del ombligo o cualquier objeto que tenga forma de ombligo (Barrera, 1980: 812). Erik Velásquez García (2016: 16) ha mencionado en su traducción del Códice Dresde, que ya Miller y también Villa Rojas (1980) habían identificado la flor como el ombligo, ya que es muy similar a un signo que se encuentra en $20 \mathrm{v}$ del Códice Mendoza donde en el texto se llama xictli, "ombligo". Entonces, si esta flor de la figura del Dresde es la misma que se encuentra en los murales de Tulum, debemos dar la razón a Miller y a Villa Rojas, aunque existe otra alternativa. Una entrada del Diccionario Maya Cordemex (Barrera, 1980: 813) resulta muy interesante para nuestra propuesta:

tuch lu'um (el significado literal es "tuch de tierra"):

mazorca que tiene granos o mancha

tuch lu'um u ko (el significado literal es "tuch de tierra su grano")

granado mal (la mazorca)

Podríamos entender, por lo tanto, que en algunos contextos tuch se identifica con la mazorca, reforzando nuestra propuesta.

El balché

En algunos estudios anteriores se ha aceptado que las decoraciones de flores y frutos, que llenan muchos de los espacios vacíos de los murales de Tulum (Figuras $16 \mathrm{a}, \mathrm{d})$, serían representaciones de plantas de frijol, pero en este trabajo las identificamos con el balché (Figuras 16b-f). Éste es el árbol del vino mencionado por fray Diego de Landa (2008: folio 59v), con cuya corteza y miel se elaboraba una bebida alcohólica fermentada y utilizada ritualmente desde tiempos prehispánicos y hasta la actualidad. La especie del balché (Lonchocarpus longistylus), es un árbol nativo de América y se puede encontrar desde el sureste de México hasta la región del Petén en Guatemala; es endémico en el norte de Yucatán, donde crece en suelos calcáreos. Su tronco es recto y corto, con una copa grande y extendida de ramas finas, con flores muy vistosas de color púrpura-violeta, que aparecen dispuestas en racimos (Figuras 16b, c). Los frutos son vainas oblongas y aplanadas, de color café claro cuando están maduros. Cada fruto contiene una o varias semillas que son visibles desde el exterior a contraluz, de manera muy semejante a como se representan en los murales (Figuras 16e, f).

La fructificación del balché ocurre de abril a junio, y la floración durante septiembre y octubre, lo que coincide con la dobla de las mazorcas y la cosecha de primicias del maíz nuevo. El balché aparece representado también en los códices, principalmente en el Madrid y en menor medida en el Dresde. El Madrid es especialmente interesante puesto que representa el árbol del balché en su época de fructificación, con el tronco de color azul, alternando con otro árbol floreciente 


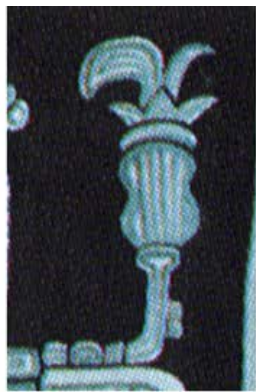

a

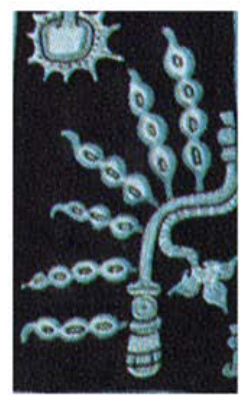

d

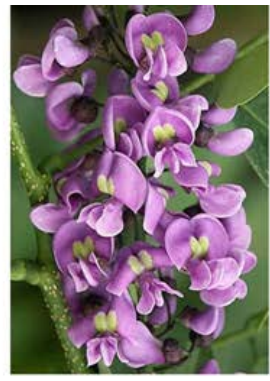

b

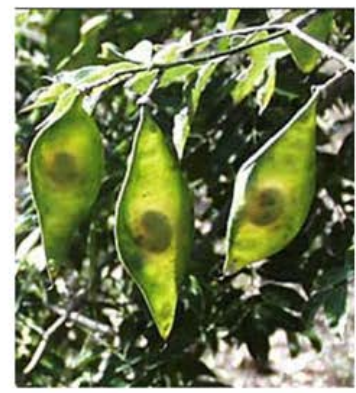

e

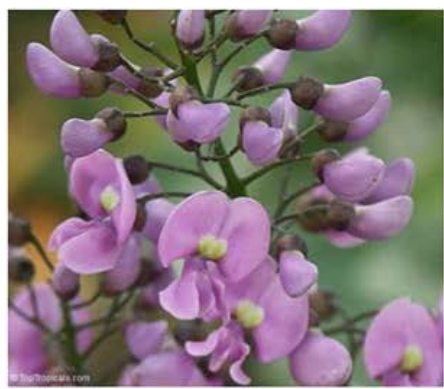

C

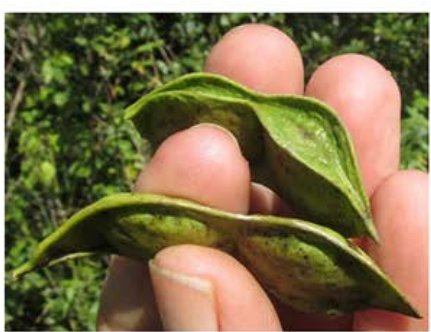

$f$

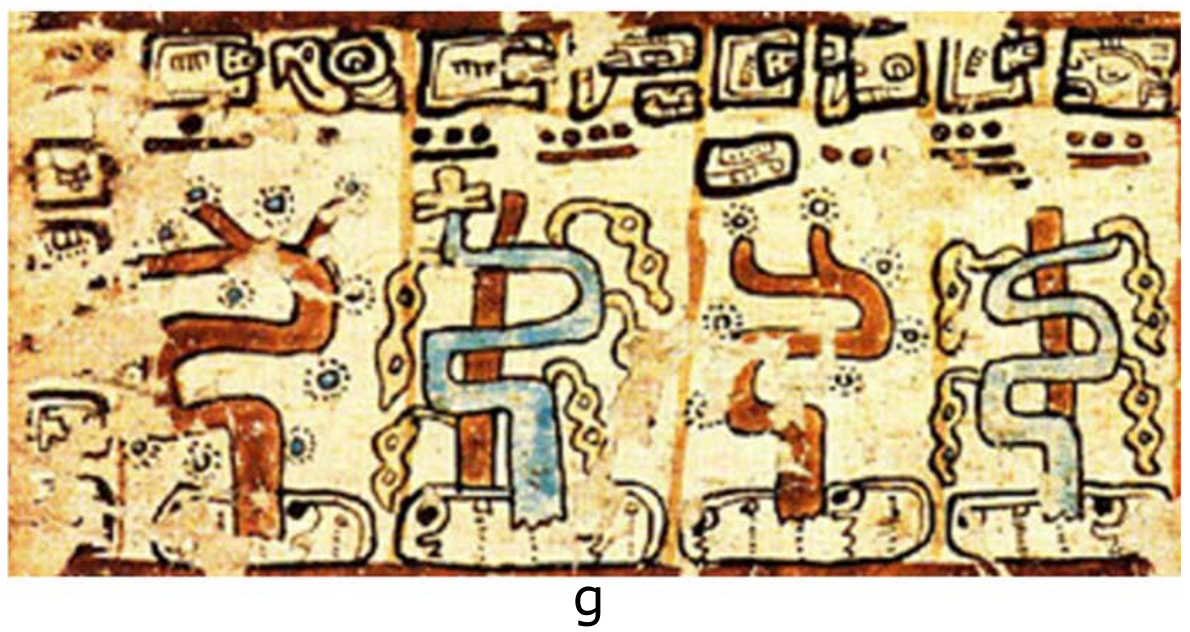

Figura 16. a-f) Flores y frutos de balché en el Templo de los Frescos y en la realidad;

g) Representaciones del árbol del balché en el Códice Madrid (1967: 25b). 
con el tronco pintado en rojo (Figura 16g), que podría ser el mismo balché en época de florecimiento.

En cuanto al nombre balche', la raíz bal significa doblar, corchar o torcer hilos o hebras, el contenido de algo, así como esconder y lo escondido (Barrera, 1980: 31). Aparte de referirse al árbol Lonchocarpus longistylus (che es un clasificador para árbol en maya yucateco), la voz balché se refiere también al cordel con que las indias atan sus telas, así como a la medida de media fanega (unos 22 litros). De acuerdo con los registros de los frailes, el uso del balché en las fiestas religiosas era muy frecuente en el periodo de la Conquista, pero el estudio del consumo de alcohol entre los mayas prehispánicos no ha recibido mucha atención hasta ahora. Para el periodo Clásico existen representaciones de actividades con bebidas embriagantes, en ocasiones asociadas a lavativas con enemas que han sido ampliamente tratados (Figura 17b; Barrera y Taube, 1987). En las vasijas polícromas de este periodo, la bebida es referida usualmente como chi', y se ha propuesto, con reservas, una identificación con el pulque (Houston, Stuart y Taube, 2006: 116-117).

Esta relación de voces para el alcohol y el hilo torcido que aparece en la palabra balche' puede tener su explicación en varias vasijas del Clásico que muestran ollas apiladas y atadas con cordeles a un marco de madera, listas para ser transportadas (Figura 17b). Aún más, una de ellas ostenta directamente el motivo de petate en su centro (Figura 17a). En cuanto a la identificación con el pulque deberá aún resolverse el problema de la ausencia de esta planta entre los mayas; la posibilidad de que el chi' del Clásico corresponda a la misma bebida que el balché del norte de Yucatán en el Posclásico merece consideración y mayor estudio.
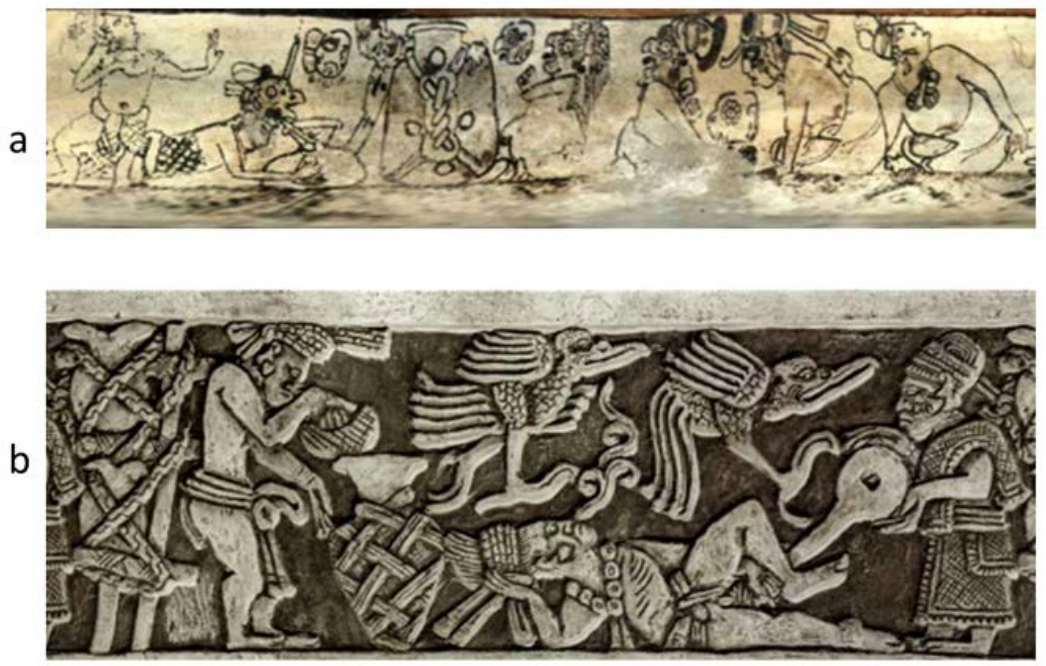

Figura 17. Representaciones de vasijas encordadas: a) Catálogo Kerr, s.f.: \#1900; b) Catálogo Kerr, s.f.: \#1550. 


\section{Conclusiones}

La relación de los murales de Tulum con la agricultura del maíz es conocida desde los primeros estudios, por la abundante presencia de elementos como las mazorcas y por las representaciones inequívocas de los dioses del maíz, la lluvia y la fertilidad. Otras asociaciones con divinidades como el dios solar, la diosa de la luna y la serpiente emplumada, Quetzalcóatl, han sido también propuestas (Lothrop, 1924; Fernández, 1945a; Miller, 1982; Milbrath, 1999; Lombardo, 2001; Taube, 2010, entre otros). En este trabajo nos hemos enfocado en algunas identificaciones iconográficas en los murales de Tulum, que nos permiten adentrarnos más en su significado.

De las deidades representadas, las más frecuentes son las de Chahk y K'awil. No obstante, la identificación de Quetzalcóatl y Xólotl es de destacarse, dado que es la primera identificación de la figura de estos dioses en Tulum. Aparecen por sí solos en la columna, y no participan de los rituales del Mural 2. En cuanto a la parafernalia ritual de objetos cerámicos hemos mostrado la presencia en los murales de verdaderas contrapartes arqueológicas, tales como incensarios efigie y de pedestal, estatuillas o ídolos y contenedores de líquidos, característicos de Mayapán y Tulum durante los siglos xIII y xIv. Esto confirma que los rituales representados en los murales eran efectivamente escenificados en Tulum con motivo de fiestas religiosas relacionadas con la agricultura del maíz.

En cuanto a los elementos zoomorfos y fitomorfos de los murales, hemos mostrado cómo las serpientes entrelazadas se refieren a Chahk y posiblemente K’awil, y su disposición cuadrangular enmarcando las escenas podría tener relación con las medidas realizadas con cuerdas para el trazado de la milpa y de los espacios rituales. Entre los elementos que aparecen a lo largo del cuerpo de las serpientes entrelazadas destacan la trenza o petate, que tiene diversos niveles de significado, y un elemento identificado con una flor, que nosotros proponemos representa mejor una mazorca. Finalmente, presentamos la identificación de las flores y frutos del balché, que encajan dentro del contexto de la agricultura del maíz y nos permiten entender el contexto temporal de los murales del Templo 16.

Es relevante el hecho de que muchos elementos iconográficos presentes en los murales del Templo 16 coinciden con la estación otoñal. Así, la floración del balché ocurre durante septiembre y octubre, mientras que, en el cultivo del maíz, en octubre se da la dobla de las mazorcas y la cosecha de primicias. Coincidentemente, en el cultivo de la miel, en octubre se da la cosecha de la miel de tajonal, la cual es necesaria para la fermentación del balché. Wahikol es la ceremonia de la primicia de la milpa (Barrera, 1980: 906), es decir el banquete o comida de la milpa, que aún se celebra en el norte de Yucatán, donde ha sido estudiado por varios autores.

El wahikol comparte algunos de los fines de las otras ceremonias para la milpa; siempre es expresión de agradecimiento por las bondades recibidas de las divinidades, 
como también una petición para la protección del terreno y del dueño y su familia. El rasgo que define la ceremonia se manifiesta en la presentación de los primeros frutos de la cosecha que se ofrecen a los dioses en la mesa-altar colmada de los productos de la tierra, además de las consabidas ofrendas que son parte de las otras ceremonias (Gubler, 2017: 58).

Las representaciones de los murales del Templo 16 de Tulum podrían así estar presentando una ceremonia de wahikol, una presentación pública de las primicias de la cosecha a los dioses, que debió haber sido escenificada por los altos jerarcas y diversos sacerdotes y sacerdotisas.

\section{BIBLIOGRAFÍA}

Barrera Rubio, Alfredo y Karl Taube

1987 "Los relieves de San Diego: una nueva perspectiva”, Boletín de la Escuela de Ciencias Antropológicas de la Universidad de Yucatán, 14 (83): 3-18.

Barrera Rubio, Alfredo, Carlos Peraza, Pedro Delgado y Bárbara Escamilla 2001 Le Crepuscule des Mayas. Amiens: Musée de Picardie.

Barrera Vásquez, Alfredo (ed.)

1980 Diccionario Maya Cordemex. Mérida: Ediciones Cordemex.

Bíró, Péter y Eduardo Pérez de Heredia

2016 "The Caracol Disk of Chichén Itzá (929-932 CE): Some Thoughts on Epigraphy and Iconography”, Estudios de Cultura Maya, XLVIII: 129-162. DoI: http//dx.doi.org/10.19130/iifl.ecm.2016.48.760.

Boucher, Sylviane y Yoly Palomo

2005 "Diálogo con las divinidades. Cosmos, dioses, ritos y ofrendas entre los antiguos mayas", I'inaj. Semilla de maíz, 13: 3-30.

Boucher, Sylviane y Lucía Quiñones

2007 "Entre mercados, ferias y festines: los murales de la Subl-4 de Chiik Nahb, Calakmul”, Mayab, 19: 27-50.

Brainerd, George W.

1958 The Archaeological Ceramics of Yucatan. Berkeley y Los Angeles: University of California Press (Anthropological Records, 19).

Bricker, Harvey H. y Victoria Bricker

2011 Astronomy in the Maya Codices. Memoirs of the American Philosophical Society Held at Philadelphia for Promoting Useful Knowledge, tomo 265. Philadelphia: American Philosophical Society. 
Escalona Ramos, Alberto

1946 "Algunas ruinas prehispánicas en Quintana Roo”, Boletín de la Sociedad Mexicana de Geografía y Estadística, 61: 513-628.

Fernández, Miguel Ángel

1945a "Las Ruinas de Tulum I", Anales del Museo de Arqueología, Historia y Etnografía, 3: 109-115.

1945b "Las Ruinas de Tulum II”, Anales del Instituto Nacional de Antropología e Historia, 1: 95-105.

Förstemann, Ernst

1892 Die Maya Handschrift der Köneglichen öffentlichen Bibliothek zu Dresden. Zweite Auflage. Mit 74 Tafeln in Chromo-Lichdruck. Dresden: R. Bertling. (Foundation for Advancement of Mesoamerican Studies). Disponible en: <http://www. famsi.org/mayawriting/codices/dresden.html $>$ [consultado el 10 de junio de 2019].

Grube, Nikolai, Alfonso Lacadena y Simon Martin

2003 Chichén Itzá and Ek Balam. Notebook for the XXVIIth Maya Hieroglyphic Forum at Texas, March, 2003. Austin: Departamento de Historia, Universidad de Texas.

Gubler, Ruth

2017 Ritos agrícolas y ceremonias curativas en Yucatán. México: Universidad Nacional Autónoma de México, Instituto de Investigaciones Filológicas (Colección Mayab: Urbimbre de Identidades, 2).

Hill, Jane $\mathrm{H}$.

1992 “The Flower World of Old Uto-Aztecan”, Journal of Anthropological Research, 48: 117-144.

Houston, Stephen, David Stuart y Karl Taube

2006 Memory of Bones: Body, Being and Experience among the Classic Maya. Austin: University of Texas Press.

Howe, George

1911 “The ruins of Tuloom”, American Anthropologist, 13 (4): 539-550.

Kaufman, Terrence y John Justeson

2003 Preliminary Mayan Etymological Dictionary. Foundation for the Advancement of Mesoamerican Studies, Inc. Disponible en: <http://www.famsi.org/ reports/01051/index.html $>$ [consultado el 17 de junio de 2019].

Kerr, Justin

s.f. Maya Vase Date Base, Foundation for the Advancement of Mesoamerican Studies, Inc. Disponible en: <http://research.mayavase.com/kerrmaya.html> [consultado el 17 de junio de 2019]. 
Landa, fray Diego de

2008 Relación de las cosas de Yucatán. Versión de Erik Boot. Original ca. 1560. Edición electrónica preliminar de Erik Boot que se basa en una versión de microfilme del manuscrito original y las ediciones de Rivero Dorado de 1985 y Garibay K. de 1986. Rijswijk: Manuscrito no publicado.

Lizardi Ramos, César

1939 "Exploraciones arqueológicas en Quintana Roo", Revista Mexicana de Estudios Antropológicos, 3 (1): 46-53.

Lombardo de Ruiz, Sonia

2001 "Los estilos en la pintura mural maya”, La pintura mural prehispánica en México II. Área Maya, tomo III: Estudios, pp. 84-154, Beatriz de la Fuente y Leticia Staines (eds.). México: Universidad Nacional Autónoma de México, Instituto de Investigaciones Estéticas.

Lombardo de Ruiz, Sonia, Alfredo Barrera Rubio, Martine Fettweiss-Vienot y Rubén Maldonado (eds.)

1987 "La pintura mural", La pintura mural maya en Quintana Roo, pp. 49-78. México: Instituto Nacional de Antropología e Historia (Colección Fuentes).

López Austin, Alfredo

2016 “La verticalidad del cosmos”, Estudios de Cultura Náhuatl, 52: 119-150.

Lothrop, Samuel

1924 Tulum. An Archaeological Study of the East Coast of Yucatan. Washington, D.C.: The Carnegie Institution of Washington.

Madrid Codex

1967 Codex Tro-Cortesianus. Graz: Akademische Druck-und Verlagsanstalt, Foundation for the Advancement of Mesoamerican Studies (Codices Selecti Series, 8). Disponible en: <http://www.famsi.org/research/graz/madrid/index.html> [consultado el 10 de junio de 2019].

Maldonado, Rubén

1987 "La arqueología de la Costa Oriental”, La pintura mural maya en Quintana Roo, pp. 11-41, Sonia Lombardo, Alfredo Barrera, Martine Fettweis-Viénot y Rubén Maldonado (eds.). Mérida: Instituto Nacional de Antropología e Historia, Gobierno del Estado de Quintana Roo (Colección Fuentes).

Masson, Marilyn y Carlos Peraza

2005 "Nuevas investigaciones en tres unidades residenciales fuera del área monumental de Mayapan”, Los investigadores de la cultura maya, 13 (2): 411-424. Campeche: Universidad Autónoma de Campeche.

Milbrath, Susan

1999 Star Gods of the Maya: Astronomy in Art, Folklore and Calendars. Austin: University of Texas Press. 
Milbrath, Susan, James Aimers, Carlos Peraza y Lynda Florey

2008 "Effigy Censers of the Chen Mul Modeled Ceramic System and their Implications for Late Postclassic Maya Interregional Interaction”, Mexicon, 30 (5): 104-112.

Milbrath, Susan y Carlos Peraza

2003 "Revisting Mayapan, Mexico's Last Maya Capital”, Ancient Mesoamerica, 14 (1): 1-46. DoI: https://doi.org/10.1017/S0956536103132178.

Miller, Arthur G.

1982 On the Edge of the Sea: Mural Painting at Tancah-Tulum, Quintana Roo, México. Washington, D.C.: Dumbarton Oaks, Harvard University.

Morley, Sylvanus

1917 "Ruins of Tuloom, Yucatan: The Record of a Visit of the Carnegie Institution Central American Expedition, 1916, to an Important but Little Known Ancient Maya City: Tuloom Has Been Inaccessible since 1848 because of Indian Hostility", American Museum Journal, 17: 190-204.

Paxton, Meredith

2010 "Implicaciones cronológicas de la pintura mural de Tulum, Quintana Roo”, $L a$ península de Yucatán: investigaciones recientes y cronologías alternativas, pp. 279301. Campeche: Universidad Autónoma de Campeche.

Peraza, Carlos y Susan Milbrath

2010 “El Escribano de Mayapán, Yucatán”, Arqueología Mexicana, 104: 18-20.

Pérez de Heredia, Eduardo

2010 "Ceramic Contexts and Chronology at Chichén Itzá, Yucatan, Mexico", tesis de doctorado en Arqueología. Melbourne: Universidad La Trobe. Disponible en: <www.wayeb.org/dowloCE/theses/Pérez_2010.pdf> [consultada el 14 de mayo de 2017].

Robertson, Donald

1970 "The Tulum Murals: The Ancient International Style of the Late Postclassic", Proceedings of the 38 International Congress of Americanists, 2: 77-88. Munich: Kommissionsverlag Klaus Renner.

Sanders, William

1960 "Prehistoric Ceramics and Settlement Patterns in Quintana Roo, México", Contributions to American Anthropology and History, 60: 155-264. Washington: Carnegie Institution of Washington (Carnegie Institution of Washington Publication, 606).

Schele, Linda y Peter Mathews

1998 The Code of Kings: The Language of Seven Sacred Maya Temples and Tombs. Nueva York: Scribner. 
Schellhas, Paul

1904 Representations of Deities of the Maya Manuscripts. Cambridge: Peabody Museum, Harvard University (Papers of the Peabody Museum of American Archaeology and Ethonology, vol. 4, núm. 1).

Schmidt, Peter

2007 "Birds, Ceramics, and Cacao: New Excavations at Chichén Itzá, Yucatán”, Twin Tollans: Chichén Itzá, Tula, and the Epiclassic to Early Postclassic Mesoamerican World, pp. 151-203, Jeff K. Kowalski y Cynthia Kristan-Graham (eds.). Washington, D.C.: Dumbarton Oaks Research Library and Collection.

Schmidt, Peter, Bíró Péter y Eduardo Pérez de Heredia

2018 "El Templo de los Búhos de Chichén Itzá y su emplazamiento cronológico: una nueva propuesta", Estudios de Cultura Maya, LII: 11-49. Dor: https://doi. org/10.19130/iifl.ecm.2018.52.913.

Smith, Michael

2003 "Information Networks in Postclassic Mesoamerica", The Postclassic Mesoamerican World, pp. 181-185, Frances Berdan y Michael E. Smith (eds.). Salt Lake City: University of Utah Press.

Smith, Robert E.

1971 The Pottery of Mayapan. Cambridge: Harvard University (Papers of the Peabody Museum, 66).

Taube, Karl

1992 The Major Gods of Ancient Yucatan. Washington, D. C.: Dumbarton Oaks (Dumbarton Oaks Pre-Columbian Art and Archaeology Studies Series, 32).

2010 "At Dawn's Edge: Tulum, Santa Rita, and Floral Symbolism in the International Style of Late Postclassic Mesoamerica", Astronomers, Scribes, and Priests. Intellectual Interchange between the Northern Maya Lowlands and Highland Mexico in the Late Postclassic Period, pp. 145-191, Gabrielle Vail y Christine Hernández (eds.). Washington, D.C.: Dumbarton Oaks Research Library and Collection.

Tozzer, Alfred M.

1907 A Comparative Study of the Mayas and the Lacandones. Nueva York: Macmillan.

Vaillant, George

1938 "A Correlation of Archaeological and Historical Sequences in the Valley of Mexico", American Anthropologist, 40 (4): 535-573.

1940 "Patterns in Middle American Archaeology", The Maya and Their Neighbors, pp. 295-305, Clarence L. Hay, Ralph L. Linton, Samuel K. Lothrop, Harry L. Shapiro y George C. Vaillant (eds.). New York: D. Appelton-Century Company.

Velásquez García, Erik

2016 "Códice de Dresden: Parte 1, Edición facsimilar", Arqueología Mexicana, Edición Especial, 67. 
Villa Rojas, Alfonso

1980 "La imagen del cuerpo humano según los mayas de Yucatán", Anales de Antropología, 17 (2): 31-46. México.

Wagner, Elizabeth

2005 "Nudos, bultos, muertos y semillas: algunas observaciones en torno al título b’olonz'ak(b'u) ajaw', Ketzalcalli, 1: 28-41.

Willard, Theodore Arthur

1926 The City of Sacred Well. Nueva York y Londres: Century Co.

Eduardo Pérez de Heredia. Mexicano. Licenciado en Historia con especialidad en Antropología y Etnología de América por la Facultad de Geografía e Historia de la Universidad Complutense de Madrid; arqueólogo por la Facultad de Ciencias Antropológicas de la Universidad Autónoma de Yucatán y doctor en Arqueología por la Universidad La Trobe, Australia. Actualmente es investigador independiente y ha colaborado en diversos proyectos arqueológicos de excavación y restauración arquitectónica del Instituto Nacional de Antropología e Historia de México, destacando Uxmal y Kabah, así como Chichén Itzá, donde se desempeñó como ceramista del proyecto. Entre sus publicaciones recientes se encuentran: "K'ak'Upakal K'inich K'awil and the Lords of the Fire: Chichen Itza during the Ninth Century", "La organización política y el paisaje de Chichén Itzá, Yucatán, México, en el periodo Clásico Terminal (830-930 d.C.)", "El Templo de los Búhos de Chichén Itzá y su emplazamiento cronológico: una nueva propuesta", todos en coautoría.

kakupakal@gmail.com

Péter Bíró. Húngaro. Licenciado en Historia por la Universidad de Szeged, Hungría; maestro en Estudios Mesoamericanos por la Universidad Nacional Autónoma de México, y doctor en Arqueología por la Universidad de La Trobe, Australia. Es investigador independiente, especializado en epigrafía e historia. Desarrolla actualmente proyectos de investigación centrados en la historia de Chichen Itzá, la epigrafía y el arte de Copán y la etnogénesis de los itzáes. Entre sus publicaciones más recientes se encuentran "Daylight Upon Dark Waters: A New Reading of the Digraph T501 [544]", "El Templo de los Búhos de Chichén Itzá y su emplezamiento cronológico: una nueva propuesta", "The Caracol Disk of Chichen Itzá (929-932 CE): Some Thoughts on Epigraphy and Iconography" y "A New Teotiwa Lord of the South: K'ahk' Uti' Chan Yopat (578-628 C.E.) and the Renaissance of Copan", esta última como único autor.

bpetr30@gmail.com 
Sylviane Boucher. Mexicana. Arqueóloga por la Universidad de Pennsylvania en Filadelfia, Estados Unidos, y maestra en Antropología por la Universidad de las Américas, Puebla. Es investigadora del Instituto Nacional de Antropología e Historia adscrita al Centro Yucatán. Ha participado en diversos proyectos arqueológicos en los Estados Unidos, así como en México, en Yaxchilan, Chiapas; Comalcalco, Tabasco; Hochob, Chicanná y Calakmul, Campeche; Sayil y Kabah, Yucatán. Sus líneas de investigación se han centrado en el análisis de materiales cerámicos arqueológicos y la distribución y producción de cerámica maya en la península de Yucatán, así como en la curaduría de colecciones cerámicas, como responsable de la Ceramoteca del Centro inaH Yucatán. Entre sus publicaciones más recientes están "Vasijas Estilo Códice de Calakmul. Narraciones mitológicas y contextos arqueológicos", "Tradición y arte cerámico" y "Discriminación visual como determinante de estilo y asignación tipológica de la cerámica Códice en Calakmul, Campeche”, esta última en coautoría.

sylvianemariemad@gmail.com 